\title{
O CURRÍCULO DE FÍSICA: análise, compreensão e crítica dos professores
}

\author{
THE PHYSICS CURRICULUM: analysis, comprehension and criticism of professors
}

\author{
Celso do Prado Ferraz Carvalho \\ Alexandre Afranio Hokama Silva²
}

Resumo: $O$ texto em tela tem como objetivo apresentar a perspectiva que professores da disciplina de física, que trabalham na rede estadual de ensino de São Paulo, possuem sobre o currículo oficial, implementado a partir de 2008, como parte do Programa São Paulo Faz Escola. Nosso intento é relatar como esse grupo de professores compreendem as demandas postas pelo currículo oficial e quais impactos produziram em seu trabalho. Na construção desse processo definimos um grupo de professores de física e realizamos um conjunto de entrevistas. As entrevistas foram estruturadas a partir de quatro blocos que trataram de formação, carreira, trabalho e prática em sala de aula. Os professores criticam o fato de não terem participado do processo de elaboração do currículo, argumentam que foram desconsideradas as peculiaridades dos contextos escolares, o que ampliou a distância entre o que estabelecia os objetivos do currículo e as condições dos alunos.

Palavras-chave: Currículo de física; currículo oficial; professores de física, prática escolar; São Paulo.
Abstract: This text aims to present the perspective that teachers of the discipline of physics, who work in the State Education System of São Paulo, have about the official curriculum, which was established in 2008, as part of the São Paulo Faz Escola Program (São Paulo Makes School Program). Our intention is to report how this group of teachers understands the demands set by the official curriculum and what impacts this curriculum have produced in their work. In the construction of this process we defined a group of physics teachers and conducted a set of interviews. The interviews were structured upon four pillars that dealt with education, career, work and classroom practice. Teachers criticize the fact that they did not participate in the curriculum development process, they argue that the peculiarities of the school contexts were disregarded, which widened the distance between what stablished the curriculum objectives and the students conditions.

Keywords: Physics curriculum; official curriculum; teachers of physics, school practice; Sao Paulo.

\section{INTRODUÇÃO}

Elemento de consenso na área de educação é o fato de que a década de 1990 marca período de intensa ação reformista do Estado no campo das políticas educacionais, especificamente das políticas curriculares. Elemento comum a essa ação reformista é a influência significativa do multiculturalismo, a defesa de determinada concepção de currículo e, como decorrência, a validação de determinado conhecimento escolar.

Entendemos que essa ação reformista é parte de conjunto mais amplo de reformas do Estado, que impulsionadas a partir da década de 1990, estabeleceram as bases para adequação do país aos processos mais amplos demandados pela reestruturação produtiva em curso. Como elemento comum a justificar tal ação reformista, o discurso produzido pelas forças do capital enfatiza a necessidade de atualização e racionalização, meios necessários para superar os problemas econômicos como inflação, equilíbrio orçamentário e crescimento econômico.

\footnotetext{
${ }^{1}$ Doutor em Educação e Professor do Programa de Pós Graduação em Educação da Universidade Nove de Julho. Email: cpfcarvalho@gmail.com. Orcid: http://orcid.org/0000-0001-8703-8236.

${ }^{2}$ Doutor em Educação pela Universidade Nove de Julho e Professor da Rede Estadual de Ensino de São Paulo. Email: alexandreafranio@yahoo.com.br.orcid: http://orcid.org/0000-0002-8424-0161.
} 
Nesse processo a educação escolar ocupou espaço importante. O discurso reformista enfatizou a necessidade de adequar a escola à essas necessidades, o que implicava mudanças na gestão, nos processos de ensino, na definição de currículo e de avaliação. O discurso de situar a escola em sintonia com as mudanças socioeconômicas, culturais e tecnológicas deram a esse processo o verniz de modernidade e inovação.

Os debates travados na definição de modelos de Estado e de seus desdobramentos, estabeleceram os parâmetros para as políticas curriculares. Nessa perspectiva, e como expressão de demandas oriundas dos processos de mudança econômica, elas incorporam e adquirem determinado significado definido pela ideologia neoliberal, enfatizando seu papel de ferramenta fundamental para o desenvolvimento econômico. Essa ênfase, no caso da educação escolar básica, torna as políticas curriculares espaço central de ação.

O contexto amplo a orientar as reformas e as políticas educacionais no campo da gestão e da estruturação dos sistemas de ensino, foi definido a partir da lógica imposta pelo discurso neoliberal. Em termos de fundamentos teóricos, a relevância assumida pelas concepções pós-modernas e pelas pedagogias do aprender foi hegemônica. Exemplo desse processo é a incorporação do construtivismo nos Parâmetros Curriculares Nacionais para o Ensino Fundamental de 1997, além de uma série de ações e medidas governamentais visando a reformulação dos currículos em todo o campo escolar.

No campo do debate teórico criou-se as condições para a disseminação e ampliação de um conjunto de autores e de concepções de educação e currículo fundadas em princípios os mais diversos, definidos de forma geral como neomarxistas, pós-críticos, multiculturalistas e outros. Comum a essas concepções é a crítica que fazem ao que definem como currículo tradicional, centrado em uma perspectiva iluminista, ocidental, canônica de conhecimento. Dessa crítica emerge a defesa que fazem do multiculturalismo e a possibilidade que ele abre para ampliar a formação por meio da inclusão, da diversidade e da democratização do debate.

A disseminação do multiculturalismo no campo educacional ajudou na disseminação de uma assertiva que situa os conflitos mais amplos no campo da cultura e de suas diferenças, reforçando a defesa de uma educação multicultural. Em um contexto de aprofundamento das desigualdades sociais, produzidas pela lógica imposta pelo capital em sua expansão incontrolada, o discurso de valorização das culturas e da diversidade produziu um deslocamento do debate sobre os conflitos sociais, do campo da disputa e distribuição da riqueza socialmente produzida para o campo da identidade e da diferença. Abriuse assim, o caminho para o MEC disseminar políticas voltadas aos excluídos ou grupos minoritários. Marco desse processo foi o seminário internacional organizado em 1996 pela então Secretaria dos Direitos da Cidadania do Ministério da Justiça, denominado Multiculturalismo e racismo: o papel da ação afirmativa nos Estados Democráticos Contemporâneos. A ênfase do seminário girou em torno das possibilidades do multiculturalismo, que adaptado à realidade brasileira, embora incapaz de superar as diferenças de classe, pudesse articular essas diferenças 3 .

A hegemonia adquirida no campo do debate curricular pelo multiculturalismo deu vazão a propostas centradas em questões amplas, mas com um fio condutor comum: a crítica aos modelos denominados de tradicionais de currículo. O conjunto dessa crítica, com nuanças distintas, apresenta uma perspectiva negativa diante da razão, da ciência, da objetividade e da totalidade, enfatiza o relativismo cultural, o pluralismo a heterogeneidade e a diferença. Para Newton Duarte o multiculturalismo, como expressão do pensamento pós-moderno, mais do que romper, aprofunda tendências do pensamento burguês expressas no idealismo e no irracionalismo ${ }^{4}$.

Esse é o campo mais amplo que fundamenta a política curricular, implementada pela Secretaria de Estado da Educação de São Paulo a partir de 2007, elaborada na gestão do ex-governador José Serra (2007-2010), tendo como responsável principal Maria Helena Guimarães de Castro, à época, Secretária da Educação do Estado. A referida reforma, denominada Programa de Ação do Governo para a Educação,

\footnotetext{
${ }^{3}$ Cf. Faustino, 2006

${ }^{4} \mathrm{Cf}$. Duarte, 2004
} 
compreendeu um amplo conjunto de metas e ações. Dentre as ações desenvolvidas o programa São Paulo Faz Escola tinha como foco mudanças no âmbito do currículo e da avaliação, articulando o currículo oficial proposto, as avaliações de larga escala, o trabalho escolar e a remuneração docente.

Acompanhar a implementação dessa política e a forma como ela impactava o trabalho de professores, de coordenadores (as) de ensino, de diretores e de supervisores de ensino ocupou grande parte de nossas atividades de pesquisa.

Ao iniciarmos o trabalho de investigação partíamos do entendimento de que as escolas e seus trabalhadores também se configuram como instâncias do processo de definição das políticas educacionais, tanto por imprimirem significados próprios às políticas governamentais, sejam estaduais ou municipais, como por utilizarem sua autonomia e definirem suas próprias ações. Assim, as escolas se constituem em contextos de concepção de políticas. Revelar o processo de implementação e a percepção que dele se constrói, pode iluminar uma face oculta nos estudos sobre política educacional, a saber, as formulações que as escolas e seus trabalhadores produzem ao longo do processo de implementação.

Os projetos de pesquisa que orientaram nosso percurso tinham um duplo objetivo: realizar análise documental e bibliográfica produzida pela Secretaria de Educação de São Paulo e; realizar trabalho de pesquisa em unidades escolares, com professores (as), coordenadores (as) de ensino, diretores (as) e supervisores (as). Essa segunda etapa da pesquisa contou com a participação de um grupo amplo de pesquisadores, pois nosso intento era trabalhar com um grupo amplo e variado de escolas, bem como trabalhar com professores de disciplina específicas. No caso desse artigo, problematizamos os resultados obtidos comum conjunto de professores da disciplina de física.

\section{A FALA DOS PROFESSORES}

No processo de pesquisa optamos pela entrevista semiestruturada como instrumento de investigação. Essa opção trouxe alguns problemas, principalmente no acesso às unidades escolares e professores. Mesmo diante dessa dificuldade a escolha se mostrou correta, pois permitiu explorar as pautas previamente definidas, com o entrevistador fazendo poucas perguntas e permitindo ao entrevistado discorrer livremente. As entrevistas foram realizadas de forma presencial e por telefone. Esse último recurso permitiu uma aparente tranquilidade e espontaneidade na fala dos entrevistados.

A definição dos professores a serem entrevistados foi outro aspecto que apresentou dificuldades, pois o acesso nas unidades escolares, por diversos motivos, é limitado. Em algumas situações percebeuse que a presença do entrevistador na unidade escolar era vista como uma interferência, ou até mesmo uma vigilância nos trabalhos desenvolvidos no ambiente. Noutras situações, aparentemente o grupo não estava disposto a colaborar com a pesquisa por posições particulares desconhecidas. Com isso a escolha dos professores entrevistados se deu em função da receptividade da escola e da colaboração por parte dos entrevistados. Dessa maneira, o critério para definição dos professores entrevistados foi por acessibilidade ou por conveniência

Para procurar responder à questão central que orientou nossa pesquisa, preparamos um roteiro que foi utilizado para nos guiar no processo de entrevistas. Definimos como eixos condutores da entrevista 4 blocos temáticos, abordando questões como a formação e a trajetória profissional, educação e as condições de trabalho, o ensino médio e o cotidiano do professor e, por último, o professor e o currículo de física. Os blocos foram desenvolvidos a partir de uma temática geral, que se subdividiu em questões especificas. A seguir apresentamos os resultados encontrados.

\footnotetext{
5 Os pesquisadores, em concordância com os entrevistados, definiram que os nomes seriam preservados e a identificação seria fictícia. Os professores entrevistados trabalham em duas escolas da região norte da cidade de São Paulo.
} 


\section{FORMAÇÃO E TRAJETÓRIA PROFISSIONAL}

Inicialmente apresentaremos um quadro com informações gerais dos professores que foram entrevistados.

Quadro 1: Dados gerais dos professores entrevistados

\begin{tabular}{|c|c|c|c|c|c|c|}
\hline $\begin{array}{c}\text { Ordem } \\
\text { nas } \\
\text { entrevistas }\end{array}$ & Nome & Graduação & $\begin{array}{c}\text { Pós- } \\
\text { graduação }\end{array}$ & $\begin{array}{c}\text { Tempo } \\
\text { atuando } \\
\text { na rede } \\
\text { Estadual }\end{array}$ & $\begin{array}{c}\text { Atividade } \\
\text { remunerada } \\
\text { antes de se } \\
\text { tornar } \\
\text { professor }\end{array}$ & $\begin{array}{c}\text { Modalidade } \\
\text { da } \\
\text { entrevista }\end{array}$ \\
\hline $1^{o}$ & Vagner & $\begin{array}{c}\text { Bacharelado } \\
\text { e licenciatura } \\
\text { em Física } \\
\text { (USP) }\end{array}$ & Não fez. & 20 anos & Sim & Telefone \\
\hline $2^{o}$ & Gisele & $\begin{array}{c}\text { Bacharelado } \\
\text { e licenciatura } \\
\text { em Física } \\
\text { (PUC-SP) }\end{array}$ & $\begin{array}{l}\text { Mestrado e } \\
\text { Doutorado em } \\
\text { Física } \\
\text { Aplicada. }\end{array}$ & 25 anos & Não & Telefone \\
\hline $3^{\circ}$ & Edgar & $\begin{array}{l}\text { Licenciatura } \\
\text { em Física } \\
\text { (USP) }\end{array}$ & Não fez. & 15 anos & Sim & Telefone \\
\hline $4^{\circ}$ & Fernanda & $\begin{array}{c}\text { Licenciatura } \\
\text { em } \\
\text { Matemática } \\
\text { (Faculdades } \\
\text { Hebraico } \\
\text { Brasileira } \\
\text { Renascença) } \\
\end{array}$ & $\begin{array}{c}\text { Especialização } \\
\text { em Física e } \\
\text { Matemática. }\end{array}$ & 25 anos & Sim & Presencial \\
\hline $5^{\circ}$ & Márcia & $\begin{array}{l}\text { Bacharelado } \\
\text { e licenciatura } \\
\text { em Física } \\
\text { (Universidade } \\
\text { Presbiteriana } \\
\text { Mackenzie) }\end{array}$ & $\begin{array}{l}\text { Mestrado em } \\
\text { Educação }\end{array}$ & 23 anos & Sim & Presencial \\
\hline
\end{tabular}

Fonte: Quadro elaborado pelos autores

No tocante à formação dos entrevistados, a professora Fernanda, embora formada em matemática, participou da pesquisa, pois ministra aulas de física desde o início de sua carreira. Convém salientar que essas aulas complementam sua jornada de matemática. Duas instituições tradicionais citadas nas entrevistas, PUC-SP e Mackenzie, atualmente não oferecem mais o curso de física. Tanto o bacharelado quanto a licenciatura em física são hoje, cursos oferecidos, predominantemente por instituições públicas como a Universidade de São Paulo, as Universidades Federais e os Institutos Federais de Educação. A justificativa tem sido de que a carreira no magistério desperta o interesse de poucos alunos egressos do ensino médio, conforme notícias e pesquisas amplamente divulgadas. Dessa maneira, a licenciatura em física e o bacharelado, possivelmente, são financeiramente desfavoráveis às instituições de ensino particulares.

A pós-graduação stricto sensu foi cursada por menos da metade dos participantes, uma reclamação comum é a duração da jornada de trabalho (desgastante) e a baixa remuneração que impedem a especialização. A experiência do grupo é elevada, apesar da escolha ter sido feita em função da acessibilidade, isso significa que os professores já vivenciaram mais de uma mudança na rede estadual de ensino, no tocante às políticas educacionais.

Quatro entrevistados exerciam atividade remunerada antes de ingressar no magistério e quase todos cursaram a graduação exercendo atividade nem sempre relacionada com o magistério. O perfil dos 
graduandos que trabalha e estuda, relaciona-se em geral, com alunos oriundos de classes sociais menos favorecidas que precisam aliar as duas atividades. Pesquisas que procuram traçar o perfil dos alunos de cursos de graduação, tem mostrado que a maior parte, é proveniente dessa classe social.

\section{EDUCAÇÃO E CONDIÇÕES DE TRABALHO}

Nessa parte procuramos explorar as condições de trabalho, de salário, informações sobre o Sistema de Avaliação de Rendimento Escolar do Estado de São Paulo (SARESP), sobre o currículo oficial e os cadernos do professor ${ }^{6}$. De modo geral, em suas falas, os professores mencionam a precariedade do sistema educacional, sendo o baixo salário um dos fatores que desestimula a permanência dos docentes. O fato do Estado de São Paulo ser financeiramente privilegiado em relação a outras unidades da federação é mencionado como fator que deveria propiciar melhor remuneração dos professores. Essa condição faz com que parte significativa dos docentes trabalhem em mais de um cargo, ou tenham jornadas elevadas, acarretando desgaste físico e emocional. Diante de tal situação a preparação das aulas fica prejudicada, além de afetar o desempenho profissional.

Além disso, a oferta de recursos didáticos é entendida como insuficiente, pois, de modo geral, são oferecidos apenas livros e giz. Materiais como cópias para a realização de avaliações e demonstrações experimentais não são oferecidas. A seguir reproduzimos as respostas obtidas através dos professores, sobre as condições de trabalho:

E assim, o salário é baixo, ruim, e condições não muito adequadas, para não dizer péssimas, né... Poderia melhorar mais, o salário poderia ser mais confortável, mais digno. Para o profissional não precisar se desdobrar, porque quando o profissional tem tempo... o profissional de ensino tem que ter tempo para preparar aula, tempo para se organizar, né. (Professor Edgar)

A condição de trabalho é horrível, é muito ruim o salário. As condições de trabalho são muito pesadas, o professor não tem tempo de preparo profissional. Ele precisa sobreviver com um salário baixo, com condições precárias. Para você dá aula você só tem basicamente sala de aula, giz, lousa ou quadro e lousa, e uma grande dificuldade de você, usar às vezes, qualquer outro tipo de coisa que a escola possa oferecer. (Professora Márcia)

Nesse quesito era esperado que o foco das entrevistas fosse a questão salarial e as condições inadequadas de trabalho. Cabe uma observação à fala da professora Fernanda, ressaltando o desinteresse dos alunos como a principal dificuldade ao desenvolvimento de seu trabalho. Apesar de procurarmos enfocar outros aspectos referentes às condições de trabalho, estrutura educacional por vezes, a fala direcionou-se ao aspecto da remuneração salarial e jornada de trabalho.

Em relação ao SARESP, as falas dos professores questionam de forma sistemática a maneira como essa avaliação é utilizada pela Secretaria Estadual da Educação de São Paulo (SEE/SP), especificamente a política de bônus, baseada em critérios de meritocracia, associada ao Índice de Desenvolvimento da Educação do Estado de São Paulo (IDESP), que é o índice que contempla o desempenho dos alunos no SARESP. Convém ressaltar que apenas um professor demonstrou conhecer a metodologia utilizada pela Secretaria Estadual da Educação.

\footnotetext{
${ }^{6}$ Os cadernos do professor se constituem no material definido pela Secretaria de Educação para indicar o caminho e a organização das atividades escolares. Ele é dirigido a todas os professores que lecionam no ensino fundamental Il e no ensino médio. Contempla os temas e tópicos definidos pelo currículo oficial, as orientações sobre a organização das atividades em sala e outras informações. Embora seja anunciado coo material de apoio a vinculação do currículo oficial aos mecanismos de avaliação em larga escala, como o SARESP, tornam sua utilização impositiva.
} 
O SARESP não é uma medida, na realidade esse bônus foi uma maneira que o governo inventou para não dar o reajuste salarial dos professores, né. Porque ele, como ele não estava conseguindo pagar todo mundo, inventou o bônus, porque, porque o bônus, ele tem uma aparência de ser uma gratificação para quem trabalha bem. Mas na verdade não é isso, ele acaba sendo uma gratificação que não é para todos os professores... eu não quero gastar dinheiro então o que eu faço? Eu dou uma gratificação para alguns professores. Então eu invento uma metodologia, que na minha opinião é bastante furada né. Porque o SARESP, ele considera por exemplo, ele considera o fluxo de alunos, ou seja, quantos alunos que passaram de ano, é só uma das coisas que ele considera. (Professor Vagner)

Uma das críticas é de que o grupo de alunos que realiza o SARESP encontram-se nas séries finais participam do processo. Dessa maneira, o trabalho dos demais professores e o processo de aprendizagem não são analisados de maneira criteriosa, passando a ser responsabilidade de um pequeno grupo de docentes e discentes. Outro ponto levantado nas falas é o fato do bônus ser para todos os funcionários da unidade escolar. Na opinião dos entrevistados deveria ser exclusivo do professor. Além disso, mencionam que avaliar o trabalho do professor por meio do aluno apresenta vieses, pois o interesse dele em realizar uma avaliação depende de fatores que vão além da sala de aula e de aspectos pedagógicos. Em outra percepção o SARESP é encarado como um instrumento de coação, conforme descrito a seguir:

Então é.... particularmente falando eu não vejo uma ligação favorável, entendeu, que fica como se fosse um toma lá dá cá, entendeu. É interessante você ter o aumento através do SARESP? É um meio de que você colocar o professor na parede e fala assim: Olha, se vira, veja o que você consegue fazer com isso, se você quiser ganhar alguma coisa, ponto, não vejo uma ligação favorável. Eu acho o SARESP super mega interessante, mas não vejo a forma de você... vai ter uma bonificação devido o SARESP, vejo mais algo assim, mais para coagir. (Professora Fernanda)

Percebe-se que o SARESP ocupa uma posição de destaque na construção do IDESP e, portanto, na bonificação recebida pelos professores. Para eles, a princípio, a bonificação deveria ser um incentivo e um mecanismo para valorizar o trabalho do professor, aliado a uma melhora dos índices educacionais. Entretanto, parece que o efeito obtido foi o oposto, os professores não reconhecem o bônus como uma motivação, além de perceberem o mesmo como elemento de pressão. Os professores têm a percepção de que seu trabalho é avaliado de maneira indireta e impessoal. Eles não consideram que a avaliação dos alunos consiga indicar de maneira adequada o processo pedagógico que ocorre nas salas de aula. Entretanto, eles não se recusam a ser avaliados, a frase a seguir demonstra uma parte dessa percepção:

Por exemplo que a prova do mérito é uma forma de você realmente avaliar se o professor tem capacidade ou não... tinha que ter mais alguma coisa para avaliar o seu trabalho em sala de aula, mas sei lá... é aquilo, tem bons e ruins em todos os lados. O processo com que eles fazem tem um lado bom e tem um lado ruim. (Professora Gisele)

Os professores criticam a associação do SARESP com a política de bonificação e defendem mudanças na política de valorização dos profissionais da educação aliada aos índices educacionais.

\section{ENSINO MÉDIO, A DISCIPLINA DE FÍSICA E A CONDUÇÃO DAS AULAS}

Nesse quesito procuramos identificar como os professores compreendem o ensino médio dentro da formação do aluno, a importância da disciplina de física e de maneira geral como são conduzidas as aulas.

O ensino médio é a parte final da educação básica, dessa maneira qualquer política para esse nível de ensino deveria almejar a melhor formação dos alunos, facilitando a inserção no mercado de trabalho 
e propiciando um ingresso adequado no ensino superior. A memória de experiências dos professores quando frequentaram o ensino médio é usada como comparação e, também, inspiração para suas aulas. O saudosismo é latente ao afirmarem que antigamente o ensino apresentava melhor qualidade, apesar de terem a clara consciência de que se tratava de um ensino com características seletivas. Na sequência apresentamos uma passagem reflete este aspecto:

Eu sei porque isso eu tentei fazer no começo, eu tentei fazer isso né. Eu tentei dar o mesmo ensino médio que eu tinha recebido na minha formação, que era o ensino médio de bom nível, eu sei que os meus professores eram muito bons. Tanto é, que eu entrei na USP sem cursinho, então daí você, dá pra você, dá para entender que os caras eram bons né. Mas naquela época também, a maioria dos alunos não conseguia acompanhar, eu lembro que teve um ano... só que naquela época não existia o SARESP, nem a preocupação de você fazer promoção automática... teve um ano que foram reprovados quase todos os alunos em química e física, quase todos os alunos da Classe. (Professor Vagner)

Algumas respostas demonstram insatisfação com a atual situação:

Quer saber o que eu acho do ensino médio? Eu acho que ensino médio é uma porcaria, que não serve para nada. O aluno não é formado em nada, ele não é capacitado para nada.... caso é o seguinte, antigamente existia... o científico, o clássico e o normal, que era bem definido, o que que você queria ser, se queria ser professor do ensino básico, fundamental I, você ia fazer normal, se você queria ciências exatas, você ia pra científico, se você queria ciências humanas e biológicas, você ia pra clássico. Aí, certo, o governo achou por bem, né, o Federal, igualar todo o país e aí que fez o tal colegial, que depois virou ensino médio. Conclusão, o aluno não é formado para nada, ele não sai capacitado para nada, nem para fazer vestibular também. Tem pessoas que falam... não, é para fazer vestibular, o ensino, nem para isso, certo. Então eu acho que do jeito que está, não serve para nada, eu prefiro o que ele está propondo agora para voltar o que era. (Professora Gisele)

É uma fala lacônica, que manifesta uma visão derrotista da escola e da educação. Por outro lado, encontramos também falas que enaltecem a formação propedêutica propiciada pelo ensino médio, como na resposta a seguir:

O ensino médio é uma parte importante da vida do estudante, é uma parte que ele está fazendo um link, com o estudante, do fundamental... o médio, né. Aqueles 3 anos para o cara pular para um nível que é uma faculdade, um curso tecnólogo, técnico, o ensino médio, ele é importante na vida do estudante... Agora... como é.... como se dá esse ensino médio, é que é o problema...o público é um negócio assim gritante, ruim, é uma manipulação de massa e eles para manipular massa, eles oprimem o profissional de educação fazendo ou deixando ele sem condições de trabalho e aí tudo é uma manipulação... (Professor Edgar)

Percebe se que a expectativa que os professores possuem do ensino médio difere daquela defendida no Currículo Oficial Paulista. A primeira impressão é que o currículo atual e suas principais orientações são desconhecidos pelos profissionais da educação. E mesmo que os objetivos sejam conhecidos, a maneira como o ensino médio é interpretado, em linhas gerais, é encarado como uma fase preparatória, propedêutica. Isso se deve possivelmente a formação dos professores, oriundos de um ensino tradicional. Associado a esse aspecto, os professores relatam descontentamento com a atual condição do ensino médio, tanto em relação ao que é proposto, quanto em relação ao interesse demonstrado pelos alunos nessa fase da educação básica. 
Em relação à importância da física para a formação dos alunos do ensino médio, verifica-se que os professores expressam empolgação com a disciplina.

O ensino de física é importante por demais para a sociedade, porque assim, é uma matéria que não é matemática, não é como se confunde, né, não é uma matéria.... Embora seja uma matéria antiga, ela abre a mente, ela tem um cunho de raciocínio lógico, de esclarecimento, a física não é só aprender calcular o negócio, põe o cara para pensar, né. $E$ faz o cara entender tudo, né, eu vejo que muitos alunos querem entender alguma coisa vem perguntar para o professor de Física, coisas diversas, coisas que nem compete a matéria, coisas ligadas a Biologia, o aluno vem e pergunta para o professor de física. (Professor Edgar)

A visão dos professores a respeito da física é positiva, consideram que a disciplina pode contribuir para a formação dos alunos, principalmente no sentido de auxiliar a interpretar o mundo sob a perspectiva das ciências naturais. Além disso, enxergam que a disciplina pode avançar no sentido de estimular a formação de novos profissionais para a área e aproximar o cotidiano dos fenômenos físicos. Em particular, observa-se a preocupação em apresentar a importância da física para o cotidiano dos alunos, ou seja, como uma ferramenta que pode auxiliar na interpretação dos fenômenos naturais. Manifestam interesse na interconexão com outras disciplinas, mas relatam que a concretização desse objetivo encontra grandes dificuldades, pois falta base e interesse dos alunos, e estrutura mínima nas escolas.

Na última parte desse bloco procuramos informações a respeito de como as aulas são conduzidas. Nesse trecho surgiram considerações que refletem dificuldades encontradas no desenvolvimento das aulas. A falta de recursos, principalmente para atividades experimentais denota a precariedade no tocante a materiais extras.

Não se pode responsabilizar a qualidade do ensino apenas às condições materiais, entretanto não há como secundarizar tal situação. Diante de uma disciplina (assim como as demais das Ciências da Natureza) que necessita de demonstrações, torna-se fundamental a utilização de equipamentos para demonstrações e a disponibilização de um laboratório. Assim:

Eu elaboro um questionário com muitas perguntas no começo, todo começo de bimestre, e eles recebem logo no começo do bimestre mais ou menos do que a gente vai estudar, em forma de perguntas que é para eles investigarem, eles responderem. No final eles vão me devolver esse questionário. E isso vai ser a matéria da prova também, já sabe o que vai cair na prova. (Professor Vagner)

Em razão das repostas percebemos que as práticas pedagógicas dos professores são baseadas em conceitos do ensino tradicional, com predominância de aulas expositivas. Apesar disso, parte considerável dos professores considera importante a realização de atividades experimentais. E conforme citado anteriormente, a utilização desses materiais apresenta dificuldades, pois segundo os depoimentos, dependem de recursos próprios para a efetivação da demonstração. A professora Gisele, além de dispor de recursos próprios, relatou que tem acesso à universidade pública, dessa maneira consegue utilizar materiais específicos em sala de aula.

\section{CURRÍCULO OFICIAL DE FÍSICA}

Procuramos verificar nesse tópico como o professor compreende o Currículo Oficial Paulista. A primeira questão que emerge é que para o professor o conceito de currículo está estreitamente ligado ao de grade curricular. Em função do tempo de formação do grupo pesquisado, acreditamos que os participantes cursaram o ensino médio em um período que o currículo do Estado de São Paulo era produzido pela CENP7 . O material em questão associava o currículo com a distribuição dos conteúdos

7 A Coordenadoria de Estudos e Normas Pedagógicas era responsável pela produção da política curricular. Recentemente, em 2011, como decorrência de mais uma restruturação da Secretaria da Educação, as atribuições da CENP foram incorporadas pela Coordenadoria de Gestão da Educação Básica. 
selecionados, e a carga horária da disciplina. Além disso, nos cursos de graduação, a grade curricular gera diversos cursos, sinônimo de currículo. Dessa maneira, era esperada tal associação.

Apesar dessa conexão, as respostas permitiram que pudéssemos identificar as concepções dos professores acerca do material produzido para a disciplina de física.

Então é isso que o caderno ${ }^{8}$ do aluno também faz. Começa por aí, ele começa criando um ambiente conhecido do aluno e ele faz uma coisa parecida com o que o Aristóteles faz. Ele começa a separar em classes essas coisas, é um negócio legal... legal como ele está sendo feito. Entretanto é muito conteúdo, é conteúdo em excesso em relação à carga que a gente tem de horas aula. Todo esse conteúdo que eles propõem não é possível tratar com os alunos, primeiro devido ao nível dos alunos que é muito baixo. Então eu acho que precisaria ver uma correlação, assim entre a carga que a gente tem no conteúdo que eles querem que a gente faça. Normalmente a gente não consegue porque são poucas aulas né, quando eu comecei das aulas eram 3 aulas. (Professor Vagner)

Currículo de física?! O currículo de física, sei lá... ele não é ruim, os conteúdos que tem que trabalhar não é isso?! Então você tá falando dos caderninhos... o conteúdo em si tudo bem, eu acho que é bom, o que você precisa fazer... tá, eu inverteria algumas coisas, por exemplo colocaria o início em ótica, porque ótica, a matemática dela é muito básica então seria muito mais fácil para a gente trabalhar e deixar mecânica para depois. (Professora Gisele)

Agora o currículo de física.... Eu acho que ele é inadequado, eu acho ele inadequado, eu acho que ele não colabora muito com o conhecimento de física que é uma coisa muito mais abrangente. Que precisava ser mais... ser pensado, ser mais estruturado, para ensinar realmente, não uma coisa que parece que é uma coisa paliativa, né. Eu vejo o caderno, eu vejo o currículo do governo, sim, muito encorpado, mas não dá para se aplicar aquilo sem um planejamento maior que é o que não se permite, o contexto não propicia isso aí. (Professor Edgar)

O conceito de currículo que manifestam está associado a conteúdos, que precisam ser seguidos e cumpridos. As demais características, como competências por exemplo, não são citadas. Percebe-se que currículo é um tema que causa insegurança nos professores, ao menos no momento em que eles precisam fazer tal abordagem. Apesar disso, quando analisaram a parte especifica da física, o conteúdo indicado como base do currículo, sentiram-se à vontade. Em algumas situações os professores fazem uma separação no material, os conteúdos a serem seguidos e a maneira como deve se dar (o roteiro sugerido nos cadernos do professor e do aluno). A fala da professora Gisele ilustra essa questão, concorda com os conteúdos, entretanto questiona a sugestão para o seu desenvolvimento.

Agora o material que eles dispõem.... Aí sim é horrível... primeiro, o que eles fizeram... eles pincelaram o GREF9 , certo? Que não funcionou também, eu sou da época que o GREF foi inserido na rede, também não funcionou, não tem condições de funcionar, porque o nível que é exigido ali no GREF era um nível muito mais alto do que você possa trabalhar numa sala de aula... Ah... O

\footnotetext{
${ }^{8} \mathrm{O}$ caderno do aluno contém as atividades a serem desenvolvidas de acordo com os conteúdos propostos pelo currículo oficial. Junto com o caderno do professor representa de forma explícita o mecanismo de indução da política curricular em São Paulo. Como forma de explicitar seus objetivos no caderno é constantemente mencionado a relação entre as atividades propostas e a avaliação em larga escala realizada pelo SARESP.

${ }^{9}$ Grupo de Reelaboração do Ensino de Física. Esse grupo, formado em torno de professores da Universidade de São Paulo, tiveram significativa importância na elaboração de outras propostas curriculares elaboradas a partir da década de 1980 no Estado de São Paulo.
} 
caderninho aí, as apostilas, caderno do aluno, caderno do professor tem muito erro conceitual... agora parece que estão diminuindo né... Mas ainda tem contém erro conceitual. A avaliação que eles que eles propõem não é nada condizente com o conteúdo que eles propõem para eu seguir. Nenhum aluno é capaz de fazer aquela avaliação com o conteúdo que é desenvolvido na apostila. Então acho muito ruim... então o caderno de vez em quando eu uso, um ou outro experimento que eles propõem, certo? (Professora Gisele)

O fato de o currículo oficial paulista ter inspiração no GREF (1998) provoca descontentamento por parte de alguns professores. Entretanto, observa-se que os eixos centrais do currículo são desconhecidos pelos entrevistados. Nenhum deles fez análise dos conceitos norteadores, ou seja, os comentários foram feitos baseados nas experiências anteriores ao currículo atual. Diante disso, talvez a divulgação do material e a capacitação voltada para os docentes não tenham sido realizadas de maneira adequada. A seguir tem-se a fala de dois professores justificando a utilização do material elaborado pelo Estado em sala de aula.

Por conta de muita demanda, muita pergunta da Coordenação, muita pergunta, às vezes capciosa, que eu percebo do governo para com o professor, eu comecei a utilizar o caderno. Só que o caderno é.... tem aluno que vem reclamar comigo: Professor, gostava daquela aula sua, parece que a gente aprendia, esse caderno parece que não ensina nada, não dá para entender uma coisa... às vezes tem exercício que a resposta está lá na frente e a gente não entende, não tem uma teoria pré-estabelecida para fazer a atividade, parece que esse caderno para a gente usar ele, tinha que ter várias aulas para depois executar... (Professor Edgar)

Às vezes, eu utilizo o caderno do professor e do aluno, porque eu acho uma judiação receber tanto material em papel, né, e ter que jogar tudo fora sem utilizar absolutamente nada. Então eu utilizo, aproveito algumas coisas, são interessantes, outras eu preciso complementar com a minha prática, muita coisa em sala de aula para chegar naquilo que tem ali, para que o aluno consiga desenvolver. Então eu utilizo no sentido de realmente não jogar tanto material no lixo. (Professora Marcia)

As justificativas dos entrevistados para utilizarem o material são a cobrança que recebem e o cuidado em não desperdiçar material. Apesar das falas não serem representativas de todos os professores da rede estadual, ela manifesta crítica ao fato de não se sentirem parte da elaboração do material. É evidente, que a reflexão sobre a participação dos integrantes do magistério, na elaboração de materiais e propostas que são utilizados na rede estadual, é fundamental.

\section{CONSIDERAÇÕES FINAIS}

Os dados levantados com os professores de física confirmaram o quadro geral mostrado por outras etapas da pesquisa. Revelou que a estruturação de um currículo homogêneo, a ser aplicado de forma impositiva em toda a rede estadual de ensino, gerou desconforto e um sentimento de depreciação do trabalho dos educadores. Identificamos a busca pelos (as) professores (as) em tentar estabelecer relações entre os conteúdos definidos pelo currículo oficial, orientado pela pedagogia das competências, e os objetivos estabelecidos pelo Sistema de Avaliação de Rendimento Escolar do Estado de São Paulo (SARESP). O controle do desempenho de aprendizagem dos alunos, baseadas nesses conteúdos, se constitui em um dos indicadores do Índice de Desenvolvimento da Educação do Estado de São Paulo (IDESP), mecanismo criado para aferir a pretensa qualidade das escolas.

A dificuldade que vários (as) professores (as) manifestaram em trabalhar o currículo em sala de aula revela a distância entre o pretendido e a realidade dos alunos, acentuada pelas peculiaridades existentes nas escolas de bairros periféricos. Chamou a atenção o fato de que a resistência inicial ao currículo não tenha derivado de uma recusa ideológica, dos elementos norteadores da proposta ou de 
suas concepções. Discordavam porque entendiam que os alunos não possuíam capacidade de lidar com o conhecimento proposto. Não se constitui em recusa fundada na crítica às concepções de educação e currículo orientadas pela pedagogia das competências, mas pela percepção de que ela não é adequada aos seus alunos.

Outro aspecto acentuado é a relação feita entre formação profissional e as demandas exigidas pelo currículo oficial. Para os (as) professores (as), o ensino centrado no desenvolvimento de competências e habilidades e o trabalho com ensino contextualizado e interdisciplinar, é parte de um processo que precisam se adaptar e aperfeiçoar. Mencionam dúvidas especificamente acerca do quesito avaliação. A pergunta que fazem é: como avaliar o desenvolvimento de competências pelos alunos? Sem expressar de forma objetiva, manifestam um sentimento de desprofissionalização com o novo perfil profissional que o Currículo Oficial do Estado de São Paulo estaria demandando.

Nas entrevistas é visível o processo de precarização das condições de trabalho. A rede estadual de ensino de São Paulo tem apresentado nos últimos anos uma série de problemas, que passam pela queda na remuneração, modificações na carreira, dificuldades postas pelas condições de trabalho e ausência de segurança. Embora não sejam problemas específicos do Estado de São Paulo, esses problemas chamam a atenção, pois a expectativa que emana da publicidade oficial contrasta com as condições objetivas de trabalho dos trabalhadores da educação da rede estadual de ensino. Dessa forma, na perspectiva dos (as) professores (as), as demandas da Secretaria de Educação Paulista, especificamente as derivadas do currículo oficial, recaem somente sobre os (as) professores (as) e gestores (as). Mencionam não perceberem mudanças na estrutura das escolas e no plano de carreira, assim como uma política consistente de incentivo à formação.

A articulação do currículo com a avaliação realizada pelo SARESP foi outro elemento mencionado pelos (as) professores (as). Em suas falas, apesar de manifestarem conhecimento acerca das metas estipuladas pela SEE/SP, através do IDESP, que cada unidade escolar da rede pública estadual de ensino deve atingir anualmente, e da importância de criarem condições para a melhoria da qualidade da educação pública, criticam a transformação dos resultados aferidos em um dos quesitos a compor a bônus pago anualmente aos trabalhadores. Criticam o fato de os Ocupantes de Função Atividade (OFA) terem que passar por um processo de avaliação como condição para terem aulas atribuídas no ano seguinte. Por fim, também criticavam a condição de Docentes Efetivos e os OFA ${ }^{10}$, somente conseguirem aumento de salário através do sistema de promoção funcional, em que realizam uma prova e precisam estar entre os $20 \%$ melhores classificados do Estado para garantirem sua evolução salarial.

O processo de avaliação e sua lógica de responsabilização criou uma situação em que os (as) professores (as), embora entendam a avaliação como necessária, criticam sua transformação em instrumento de opressão e imposição de políticas curriculares. Sem mencionarem diretamente, deram indícios que a desconsideração, pelos formuladores de políticas educacionais, dos elementos que envolvem o cotidiano dos (as) professores (as), suas práticas e a cultura que permeia a escola, dificultava e impedia a efetivação das políticas educacionais. Novamente verificamos que não se tratava de uma recusa explicita aos princípios, fundamentos e concepções de educação envolvida na pretendida reforma, mas sim, a recusa a um processo que não considera a objetividade imediata dos (as) professores (as) e que se impõe por meio de mecanismo que ameaçam sua condição de trabalho.

Os professores expressam sua indignação e não reconhecem o currículo oficial como legitimo, afirmando que suas propostas (sugestões) não foram incorporadas. Dessa maneira a implementação do

\footnotetext{
${ }^{10}$ Denominado Programa de Valorização pelo Mérito o programa é objeto de crítica dos professores. Entre elas o fato de que faltas, licenças médicas ou férias prémio desclassificam o candidato. Outro elemento de crítica é o fato de que a prova somente pode ser feita a cada 4 anos. No geral é uma política de valorização que desvaloriza a carreira docente, pois vincula o salário a processo de precarização do trabalho e negação de direitos.
} 
currículo tem encontrado resistência por conta da falta de identificação com o material ou, como as falas mostram, um certo descaso.

No geral a pesquisa mostra dados que permitiram verificar as dificuldades enfrentadas pelos grupos que trabalham e utilizam o currículo nas escolas. Trata-se de um caminho com diversos desvios de percurso, pois a cada etapa ocorre uma reinterpretação dos objetivos. Permitiu também firmar mais ainda nossa convicção de que durante o processo de implementação de um novo currículo, a compreensão e os significados atribuídos pelos trabalhadores das escolas, implica na construção de um novo currículo, não o oficial, mas aquele que surge da prática escolar.

O encontro entre as concepções relativistas com o pragmatismo neoliberal, quando transpostas para o debate escolar, produz mudanças significativas na compreensão que se tem do papel da escola, reduzindo sua ação às expectativas postas pelo cotidiano imediato, com a consequente desvalorização do conhecimento objetivo. Ao reduzir sua dimensão à essas demandas, as políticas curriculares tornam se meio de disseminação e de produção de novos significados à prática escolar, incorporando conceitos como competências, empreendedorismo, empregabilidade, criatividade, aprender a aprender, eficiência, eficácia e outros. Não tem sido outro o caminho seguido pelas propostas curriculares da SEE/SP. Embora a ideologia neoliberal, expressa no pragmatismo e na adaptação, seja, hoje, hegemônica nas políticas curriculares, a forma como os professores se relacionam com os objetivos que elas expressam, não é mecânica. De forma organizada ou como expressão de um cotidiano alienado, os professores constroem e atribuem outros significados ao currículo proposto. Seu trabalho marca e define caminhos que não são necessariamente os definidos pela burocracia, enfim, produzem o cotidiano escolar o currículo realmente existente, de acordo com suas condições de trabalho e convicções. Buscar a compreensão desse processo é um dos objetivos que orienta nossas pesquisas, que materializa parte de seus achados nesse artigo.

\section{REFERÊNCIAS}

CARVALHO, Celso. A reforma da educação no Estado de São Paulo e sua objetivação na prática escolar: dimensões curricular, avaliativa, gestionária e laboral. CNPQ/Projeto de Pesquisa. São Paulo, 2011, mimeo.

DUARTE. Newton. A rendição pós-moderna à individualidade alienada e a perspectiva marxista da individualidade livre e universal. In: DUARTE, Newton. Crítica ao fetichismo da individualidade. Campinas: Autores Associados. 2004. P. 197-217.

FAUSTINO, R. C. Política Educacional nos anos 1990: o multiculturalismo e a interculturalidade na educação escolar indígena. 2006. Tese (Doutorado em Educação) - Universidade Federal de Santa Catarina. Florianópolis, 2006.

GRUPO DE REELABORAÇÃO DO ENSINO DE FÍSICA (GREF). São Paulo: Edusp,4ª edição, 1998, vol 1.

GRUPO DE REELABORAÇÃO DO ENSINO DE FÍSICA (GREF). São Paulo: Edusp, 4 a edição, 1998, vol 2.

GRUPO DE REELABORAÇÃO DO ENSINO DE FÍSICA (GREF). São Paulo: Edusp, 4 a edição, 1998, vol 3.

SÃO PAULO/SECRETARIA DA EDUCAÇÃO DO ESTADO DE SÃO PAULO. Proposta Curricular do Estado de São Paulo - São Paulo faz escola. São Paulo: SEE, 2008a.

SÃO PAULO/SECRETARIA DA EDUCAÇÃO DO ESTADO DE SÃO PAULO. Caderno do Gestor. Gestão do currículo na escola. São Paulo: SEE, 2008b.

Recebido em: 22/01/2018

Aceito em: 04/03/2018

Publicado em: 26/04/2018 